\section{Emotional intelligence among auditory, reading, and kinesthetic learning styles of elementary school students in Ambon- Indonesia}

\author{
Marleny Leasa ${ }^{a, b}$, Aloysius D. Corebimac, ${ }^{c}$, Ibrohim $^{c}$, Hadi Suwonoc
}

\begin{abstract}
Students have unique ways in managing the information in their learning process. VARK learning styles associated with memory are considered to have an effect on emotional intelligence. This quasi-experimental research was conducted to compare the emotional intelligence among the students having auditory, reading, and kinesthetic learning styles in elementary school in Ambon-Maluku. Emotional intelligence was measured by a questionnaire developed based on the theory of emotional intelligence according to Goleman (1998). The learning style instrument was adapted from Fleming (2001). The results of this research show that learning styles have significant effect on emotional intelligence. Kinesthetic learners have a higher emotional intelligence than those of the auditory and reading learners, as much as $8.35 \%$ and $6.11 \%$ respectively. This research recommends that schools and teachers need to provide a conducive learning environment, including utilizing constructivist learning strategies which are appropriate with the development of the elementary school students. Further researches are required to investigate the changes of the students' learning styles along with their development into higher education levels, and its effect on their emotional intelligence.
\end{abstract}

Keywords: Auditory learning, emotional intelligence, kinesthetic learning, learning styles VARK

\section{Introduction}

Humans are required to be able to socialize with other people in this global era. Human satisfaction can no longer be measured by their wealth or their glory only, but by their values and new beneficial ways when they are communicating with other people in a particular time and in any situation, in order to find true happiness based on peace within oneself and others. Modern societies are trying to pick up inner happiness, without orienting to physical happiness. Physical and material wealth is not a guarantee of true happiness. This rationalization reflects that education should emphasize the development of students' social and emotional aspects (Berrocal \& Ruiz, 2008), so as to prepare graduates to be able to survive facing challenges of the times. Emotional intelligence is considered as an umbrella of habits, skills, attitudes, and nature (Furtner, Rauthmann, \& Sachse, 2010). According to Brackett, Mayer, and Warner (2004), people emotional intelligence determines their daily behaviors. A wellcontrolled emotion guarantees life success, otherwise a poorly-controlled emotion ensures destruction. Thus, emotional intelligence is an important soft skill.

Emotional intelligence is not taught as special subjects, and the supervision of the students' emotional development is not conducted too. The emotional components are happiness, joy, anger, fear, hate, and shame. Knowledge of emotion is indirectly taught in religious education and civic education at different levels of education in Indonesia. More specific knowledge about the emotional aspects is studied in the field of psychology. However, theoretical and practical studies training a person to escape from excessive emotional elements which bring negative impacts are not much revealed. Emotional intelligence should be developed as early as possible, especially in elementary school period, in which the students are still in their emotional formation process. Kwon \& Yakwey (2003) and Ashiabi (2000) mentioned that the elementary school age children began to recognize emotions, had relationships with others, communicated what they understood or experienced, and expressed emotion. "Children see, Children do", children more likely imitate the behavior or the examples by adults. When the adults are angry, the childreen learns how to be angry, when the adults show behaviors that help each other, the children also learn to help each other, and the other emotional behaviors. Children tend to learn from the behavior of adults around them, particularly from the immediate environment such as family and schools.

a Postgraduate Student, State University of Malang, Indonesia

b University of Pattimura Ambon, Faculty Teachers Training and Education, Department of Primary Teacher Education, Indonesia Email:marleny.leasa@fkip.unpatti.ac.id

c Universitas Negeri Malang, Faculty of Mathematics and Natural Sciences, Department of Biology, E-mail addresses: (Ibrohim) Ibrohim.fmipa@um.ac.id; (H. Suwonoc) hadi.suwono.fmipa@um.ac.id

*Corresponding author: Biology Department, State University of Malang, Il. Semarang No. 5 65145, Malang, East lava-Indonesia. Phone: +628164294487

E-mail:duran.corebima.fmipa@um.ac.id 
Emotional intelligence in this research refers to Gardner (1993) in the form of intrapersonal and interpersonal intelligence. The factors affecting low emotional intelligence of students in Ambon-Indonesia are related to the learning strategies used by teachers (Hegarty \& Angelidis, 2015) and the practice of violence. If the teacher as a single speaker in learning has no or less interaction with students, the students will have difficulties in developing their emotional intelligence both intrapersonally and interpersonally. Conventional learning or teacher centered learning commonly implemented in schools does not maximally train the students to socialize with others, serve others, accept the opinions of others, lead, resolve conflicts, communicate, and cooperate with team. As a post conflict environment, Ambon-Indonesia is a field of violence practices still occuring in elementary schools until today (Leasa \& Samallo, 2014). Teachers are not trained to use humanistic methods of education because the environment and culture of the people in Ambon-Indonesia have been entrenched in the philosophy of sago "be strong like sago tree, thorny outside but white inside". Futhermore "there is gold at the tip of the cane" is an old local proverb that is adopted in educating children. The philosophy and the proverb mean that children need to be forged, molded, and nurtured by the hard way, like the sago trees which are thorny or like cane in order to finally be white, clean as sago starch or obtain the best results as gold. Such mindsets and conducts will create possible spaces for violence practices, and there will be a notion that violence is a positive action that is useful in educating children to become successful. In conclusion, the development of emotional intelligence in schools is hindered by unfavorable climatic environments and the culture of violence which is deeply rooted in the society.

Goleman (1995) stated that emotional intelligence was useful in establishing and maintaining a harmonious relationship with others. Human life is filled with various people having different understanding as well as different managing emotions, that would affect their adaptation to different life situations. In such contexts students require emotional intelligence to overcome the challenges and problems of real life (Ghuman, 2011). Vandervoort (2006) also expressed that emotional intelligence could be regarded as a predictor of academic success. These views are in line with the research findings reported by Downey, Lomas, Clare, Billings, and Stough (2014) that women with good emotional intelligence managed to get a high score on scholastic ability. The research findings reported by Shahzada, Ghazi, Khan, Khan, and Shah (2011) revealed a positive correlation between emotional intelligence and academic ability. Emotional intelligence is needed to survive and to solve various problems of life independently and to make the best decision in the most difficult situation. Emotional intelligence also has significant effect on leadership (McCleskey, 2012; Johnson \& Stern, 2014).

Learning is more oriented only towards the empowerment of intellectual intelligence from the past until now. As a result, the whole time is mostly spent for teaching students concepts, facts, principles, theories, formulas of knowledge, and tend to ignore the emotional elements (Berrocal \& Ruiz, 2008). Emotional intelligence is not managed maximally since it is assumed that students will have emotional intelligence automatically if they have intellectual intelligence.

Educational institutions such as elementary school has a strategic role in empowering the emotional intelligence (Mayer \& Cobb, 2000; Brackett, Mayer, \& Warner, 2004). Education policy should be directed to develop the school environment as a developmental place of emotional and social intelligence. In some countries the concept is integrated into the Social Emotional Learning (SEL) based curriculum at different levels of education (laosanurak, Chanchalor, \& Murphy, 2015; Ashdown \& Bernard, 2012; Gunter, Caldarella, Korth, \& Young, 2012; Caldarella, Kramer, \& Kronmiller, 2009). Elementary school students have unique characteristics, and they require special treatment regularly and sustainably regarding their emotions. They need the assistance or guidance from their parents and teachers. Fallacy in educating children in elementary school age will affect their emotional conditions and their developmental patterns at the later stages.

Students have different characteristics such as cognitive ability, readiness for learning, motivation level, and learning styles (Demir, Kilinc, \& Dogan, 2012). There is not any individual who is exactly same with one another (Baş \& Beyhan, 2010). The learning styles used in storing and managing information also vary (Daşdemir, 2016). Some students can easily remember the information only by reading once, but some others need to read for several times. There are also some students who are able to store the information in their brain only by looking at the objects, but some others need to touch, practice, and perform a more in-depth study about a particular object. Thus, every student has unique styles of managing a learning material. Heterogeneous classes are expected to be a strategic place to accommodate the students with different learning styles.

VARK model learning style was developed by Fleming (Eom, Wen, \& Ashill, 2006). In VARK model, students are classified into four types of learners namely Visual, Auditory, Read, and Kinesthetic. Students having only one learning style are called unimodal, while students having more than one learning style are called multimodal. VARK learning styles can be identified among students, and the results are relatively stable. High-class elementary school students tend to have kinesthetic, auditory, and read learning styles (Leasa, 2014). Auditory learners tend to use their auditory senses in learning, store knowledge by listening, and usually they are eloquent. Read learners like reading, and their writings are usually neater, futhermore they do not dominate the opportunity to speak during the learning activity. Kinesthetic learners, on the other hand, use all their body parts to store information. They are more active, and cannot stay still in place.

VARK model refer to the aspect of sensory modalities (Othman \& Amiruddin, 2010), so that the optimization of learning styles can be associated with memory (Davis, 2007). A person's emotions are governed by his memory. Levine and Pizarro (2004) uncovered the correlation between emotion and memory. The research findings by Fong and Yeo (2007) asserted too that learning styles affect emotional intelligence. 
Based on this background, this study aims to reveal the comparisons of emotional intelligence among auditory, read, and kinesthetic learning styles of elementary school students. This information will be useful for elementary school learning in Ambon, Indonesia.

\section{Method}

This study was a comparative study, conducted in a quasiexperiment using pretest-posttest non equivalent control group design, of $3 \times 3$ factorial design. The first variable was the learning model, consisting of learning model level Numbered Heads Together (NHT) combined with metacognitive strategies, NHT, and conventional learning. The second variable was the learning style consisting of auditory, read, and kinesthetic learning styles. The dependent variables of this research was the emotional intelligence. This article will be more focused on learning styles instead of discussing a learning model.

The procedures of the quasi-experimental research are as follows.

- A equality tests was conducted to determine which classes are equal. Only the equal classes will be involved in this research. Then, a test will be conducted too to the samples to find out the distribution of the learning styles among the samples.

- Students from 12 sample classes were divided into three groups of treatment which were NHT, NHT combined with metacognitive strategies, and conventional learning

- Prior to the treatment, all the students were asked to fill in an emotional intelligence questionnaire.

- Treatments carried out in this study was conducted for 26 meetings. All the the groups of treatments of different types of learning received the same learning materials.

- The students' learning styles were observed during the 26 learning meetings. Futhermore the students were asked to fill in the emotional intelligence questionnaire for the second and third time.

- After receiving all the treatments, the students were then asked to fill in the same questionnaire for the last time.

\section{The Study Group}

The population of this research was all the students of class $\mathrm{V}$ in Ambon-Indonesia. The schools determined as the population is a core school consisting of 23 elementary schools spreading in three district areas, namely Nusaniwe, Sirimau, and Baguala. 12 of the 23 core schools were randomly selected as the samples of this research involving 210 students.

The student samples based on the learning style were obtained according to the determination of VARK learning styles, so that there were $20-28$ students found in a single experimental class consisting of auditory $(A)$, read $(R)$, and kinesthetic $(K)$ students. Because of the number of the visual (V) students was too small in each class and it could not comply with the data analysis requirement, the visual learning style was disregarded in this research.

Data Collection Tools
The students' learning styles were measured using learning style test by filling the questionnaire of learning styles. The learning style tests were given before the quasiexperimental research was conducted. Before the test was given, the researcher explained how to fill out the questionnaire. The learning process was conducted for 26 meetings or approximately 4 months, in which the researcher also observed the consistency of students' learning styles, as well as ensured that the results of learning style test were relevant to the students' learning styles demonstrated in observations and interviews. The learning style test results were corrected by the researcher with referring to the provided answer key.

The questionnaire related to learning styles has been constructed based on 3 indicators. The first indicator referred to the context of information gaining ( 9 items), the second indicator referred to the context of information sending ( 4 items), and the third indicator referred to the context of decision making ( 3 items). Therefore overall there were 16 items constructed. Each item contained four possible answers ( $\mathrm{V}, \mathrm{A}, \mathrm{R}$ and $\mathrm{K})$, so that from the results of the 16 item test, the students' response of each question and the total score of each learning style selection could be identified. For example: student $A$, with the scoring result of $V=2, A=4, R=2, K=8$, had $K$ learning style. If student $B$ got the scoring results of $V=3, A=5, R=3, K=5$, so he or she had bimodal (AK) learning style. Therefore, it could be concluded that each student had a specific learning style. In this research, bimodal and multimodal learning styles were ignored because the percentage was very small (Leasa, 2014).

Nelis, Quidbach, Mikolajczak, and Hansenne (2009) stated that emotional intelligence should be measured more than once. In this research for 1 semester the emotional intelligence was measured 4 times with the time interval more or less similar: first (before treatment, $1^{\text {st }}$ week of August), second (meeting $9 / 2^{\text {nd }}$ week of September), third (meeting 18/4 ${ }^{\text {th }}$ week of October), and fourth (after the end of the whole treatment, $1^{\text {st }}$ week of December). This method was conducted in order to ensure that the data of the students' emotional intelligence were still consistent.

The research instruments used were: VARK model learning style questionnaire and emotional intelligence questionnaire. The learning style questionnaire used was a learning style for young category version 7 developed by Fleming (2001) (www.vark-learn.com). The questionnaire was adapted according to the characteristics of high-grade elementary school students in Indonesia, especially in Ambon. The questionnaire of learning styles had been validated by a learning expert from Universitas Negeri Malang and had been tried out prior the research. One of the instances of the questionnaire items is:

1. You like a game which.......

a. is easy to operate

b. has unique and interesting sound

c. has practical guidance

d. has attracting appearance

The instrument for emotional intelligence was developed by the researcher referring to emotional intelligence domain according to Goleman (1998), and has passed the stages of validation and empirical test. The questionnaire 
for emotional intelligence referred to the Likert scale, with five alternative answers (strongly agree, agree, undecided, disagree, and strongly disagree). The questionnaire contained 44 statements, 22 positive statements and 22 negative statements, with the validity score of 0.611 and the reliability score of 0.963 . The time needed to fill out each instrument was between 20-30 minutes.

\section{Data Analysis and Procedures}

The data of learning styles were used to classify the students into different treatment groups based on their learning styles, and then they were descriptively analyzed. The comparison of the students' emotional intelligence based on auditory, read, and kinesthetic learning styles was analyzed by using analysis of variance supported by SPSS 17.00 program for Windows. Before the data were analyzed, the normality test was performed with One Sample Kolmogorov-Smirnov Test. The normality test results showed the normality value of $0.811(p<0.05)$ which meaning that the distribution of emotional intelligence data was normal.

\section{Results}

The data descriptions of the students' emotional intelligence viewed from the learning styles and learning models are shown in Table 1. Table 1 shows that the highest mean in all of the learning models is found in kinesthetic learning style, which are 73.6231 (NHT + Metacognitive), 70.4865 (NHT), and 64.6749 (Conventional). The lowest mean is found on the read learning style (conventional model). In conclusion, kinesthetic learning style had the highest mean (69.5274) compared with the read (65.6885) and auditory (64.1409) learning styles.

The results of analysis of variance test related to the effect of learning styles and learning model on emotional intelligence are shown in Table 2. Table 2 shows that significance value of the learning styles $(0.000)$ is smaller than $a(0.05)$. It means that there is a difference in students' emotional intelligence based on the auditory, read, and kinesthetic learning styles. LSD test is conducted to determine which of the three learning styles is significantly different. The results of the LSD test on the differences of emotional intelligence based on students' learning styles can be seen in Table 3.

Table 1. Data description of the emotional intelligence based on learning styles and learning models

\begin{tabular}{lllcc}
\hline \multicolumn{1}{c}{ Learning Model } & \multicolumn{1}{c}{ Learning Styles } & N & Mean & Std. Deviation \\
\hline Conventional & Kinesthetic & 25 & 64.6749 & 9.46824 \\
& Auditory & 25 & 62.6757 & 7.96625 \\
& Read & 23 & 61.8291 & 8.40379 \\
& Total & 73 & 63.0936 & 8.60554 \\
NHT & Kinesthetic & 24 & 70.4865 & 6.33453 \\
& Auditory & 20 & 63.9815 & 5.83460 \\
& Read & 23 & 65.7851 & 6.21379 \\
NHT + Metacognitive & Total & 67 & 66.9308 & 6.65918 \\
& Kinesthetic & 24 & 73.6231 & 5.95375 \\
& Auditory & 21 & 66.0371 & 9.85428 \\
& Read & 25 & 69.1505 & 8.17474 \\
Total & Total & 70 & 69.7499 & 8.52937 \\
& Kinesthetic & 73 & 69.5274 & 8.25217 \\
& Auditory & 66 & 64.1409 & 8.07817 \\
& Read & 71 & 65.6885 & 8.14988 \\
& Total & 210 & 66.5366 & 8.43695 \\
\hline
\end{tabular}

Table 2. The results of analysis of variance test

\begin{tabular}{lrrrrr}
\hline Source & Type III Sum of Squares & Df & Mean Square & \multicolumn{1}{c}{ F } & Sig. \\
\hline Corrected Model & $2868.312^{\mathrm{a}}$ & 8 & 358.539 & 6.001 & .000 \\
Intercept & 922626.723 & 1 & 922626.723 & 15442.746 & .000 \\
Model & 1535.749 & 2 & 767.874 & 12.853 & .000 \\
Learning Style & 1093.648 & 2 & 546.824 & 9.153 & .000 \\
Model * Learning Style & 220.247 & 4 & 55.062 & .922 & .452 \\
Error & 12008.743 & 201 & 59.745 & & \\
Total & 944572.636 & 210 & & & \\
Corrected Total & 14877.055 & 209 & & & \\
\hline
\end{tabular}

a. R Squared $=.193$ (Adjusted R Squared $=.161)$ 
Table 3. The results of least significance different (LSD) test

\begin{tabular}{clll}
\hline No. & \multicolumn{1}{c}{ Learning Styles } & Mean & Notation LSD \\
\hline 1 & Auditory & 64.231 & $\mathrm{a}$ \\
2 & Read & 65.588 & $\mathrm{a}$ \\
3 & Kinesthetic & 69.595 & $\mathrm{~b}$ \\
\hline
\end{tabular}

Table 3 shows that kinesthetic learning style has significant difference of emotional intelligence compared to the auditory and read learning styles. The emotional intelligence of the kinesthetic students are $8.35 \%$ higher than that of the auditory students, and $6.11 \%$ higher than that of the reading students.

\section{Discussion}

Comparison of Emotional Intelligence between Auditory, Read, and Kinesthetic Learning Styles

The results of the research show that learning styles have an effect of emotional intelligence. Learning styles of VARK model refer to the sensory modalities. The sensory aspects of human are auditory, read, and kinesthetic directing the information to the limbic system to be responded as emotion. Cavanaugh, Maclnnis, and Weiss (2015) confirmed that the modality of perception was capable of providing strong support to emotions. Auditory aspect reflecting the hearing modality is differentiated into harmony (discordant vs. harmonious) and the decibel level (quiet vs. loud). The dimensions of read modalities are like the rhythm of reading (hard vs. soft), and the dimensions of kinesthetic modalities are like speed (fast vs. slow). These perceptions lead to emotional response which might be positive or negative, depending on the response of each person. Emotional expression is seen in the relation of various aspects of human life every day. Goleman (1998) stated that self-regulation was one of the elements of emotional intelligence. Self-regulation refers emotion regulation, that is the ability to remain calm under pressure, or the ability to maintain and control their emotions in order to behave properly. A positive emotion regulation is the best way to minimize the negative emotional expressions (Tugade \& Fredrickson, 2007).

The research results also show that kinesthetic learning style has significant effect on the emotional intelligence compared to auditory and read learning styles. Kinesthetic learners are more likely to learn from the experience gained when they perform certain activities (learning by doing). Kinesthetic is the type of learning styles that easily accept and process information through a series of activities that move some or all parts of the body and practice the things being learned. They like moving their body (movement) and moving their hands/hand gesture (touch). Body movements are related to learning through body movements, walking, turning the body, swaying, and these activities were skillfully done. Meanwhile, hand gesture is related to the use of fingers, feel, and body touch. The fingers are quite deft and skillful to make a hand creation, to dance gracefully, to write neatly, and to draw thorough and detailed drawings. Body movements can be found when someone is dancing (Dyck, Maes, Hargreaves, Lesaffre, \& Leman, 2013). The research results of Boone \& Cunningham (1998) proved that a five-year-old child was able to decode the information related to the emotions expressed by the dancers' movement. Thus, dance is a form of emotional expression, which requires teamwork, a good adaptation from one movement to the other movements, and can develop social relationship harmony. Hertenstein \& Keltner (2011) asserted that the touch was also a sign of emotional expression in the form of sympathy and happiness. In short, body and hand movements which are appropriate and timely are another way that can be used to develop emotional intelligence.

Kinesthetic learners like to be involved in physical activity. The involvement is not confined only to the physical involvements, but especially to emotional involvement, including cognitive activity in the achievement and the acquisition of knowledge, appreciation and internalization of values in the formation of attitudes and values. Various exercises that are prepared for learners also develop their skills, emotion, self-esteem, and cognitive outcomes (Erwin, Fedewa, \& Ahn, 2013). Learning activities accompanied by physical activity make students directly involved by optimizing various senses to support learning activities, such as hear, feel, smell, and even redesign the object being studied. Thus, the experience of the kinesthetic learners become intact and there has been a maturation of the emotional elements such as motivation, leadership, and social interaction.

Kinesthetic learners activate the various organs of the body in expressing emotions. As a result, their confidence increases, and their social relationships with others become stronger. Physical activity which involves various organs of the body is an opportunity for students to express themselves as widely as possible. For example in playing or dancing, the students will try something new. Some possibilities that may occur when students are doing these activities are that students will succeed, fail, or will be encouraged keep trying hard. When the students are slowly begining to master the activity, their experience and their motoric ability are formed. Furthermore, this activity can improve students' self-confidence because they have showed independence and responsibility in expressing themselves (Walter \& Sat, 2013). Physical movements or activities are a powerful way to present and to assess the emotional expression (Thom, 2010). Physical activity enlarges the opportunities for someone to investigate his environment, expand his emotional knowledge, and develop his physical and emotional skills. Thus, the sensory experience expressed through physical activities will strengthen the emotional experience that leads to the development of emotional intelligence. Hanford (2000) added that the children could control their physical activity when they were in a social environment with their peers, and more likely to build social relationships with others and developed their social skills.

The environment is rich of factors stimulating children to be active, to investigate, and to test an object they find. The 
experience is developed by children through various physical activities. The condition is highly relevant to the development of the brain nerve which allows the child to utilize the objects in the environment effectively. Such processes make the children learn to carry out more complex tasks. The physical activity is carried out by the children in order to gain the experience in a wide variety of motion. The other goal is to improve their motor skills and control mechanisms, so that their confidence, appreciation or recognition for themselves develop positively. In addition, physical activity is helpful to show initiative, independence, and responsibility (Walter \& Hen, 2012). Thus, physical activity can encourage the development of a child's emotional intelligence.

Kinesthetic learners tend to activate the cerebellum to manage and to store information physiologicaly (Davis, 2007). Kinesthetic learners enjoy doing a variety of physical activities that facilitate them to store information. According to Leiner (2010), the cerebellum is also known to be involved in mental exercise of motor tasks, which can improve the performance and make someone become more skillful. The cerebellum is connected to the area of the brain that not only focuses on motor activity but also focuses on the mental and the sensory tasks and can automate the motor activity as well as mental and sensory skills of humans. Thus, at the same time, kinesthetic learners not only perform motor skills but also perform the other skills automatically. For example, in communication, motor activity controls speech or gestures, while the mental activity is responsible for formulating what to say. Kinesthetic learners like repetitive exercises and repetitive testing or those conducted in stages, to activate a variety of other skills simultaneously, such as communication skills, accepting the opinions of others, listening, so that the emotional intelligence becomes more well organized.

The research results of Fernandez et al. (2015) also revealed the profile of the emotional intelligence in relation to students' learning strategies in Chile. The student samples of 14-18 years old were classified into 4 profiles of students' emotional intelligence namely: 1) a group of young students having high intelligence profile, 2) a group having the dominance of low emotional attention and high improvement skills, 3) a group having high attention and low improvement skill, and 4) a group of adolescents having low intelligence. In conclusion, emotional intelligence is influenced by the learning strategies which include attention, motivation, time management, concentration, information processing, the learning objectives, and self-assessment strategies. The research conducted by Aliakbari \& Nejadian (2011) proved that there was a correlation between Myers-Briggs learning styles and the emotional intelligence in the dimensions of emotion regulation, use of emotion, and emotion ratings. Similarly, the findings of Zhang (2008) revealed that there was a correlation between a person's thinking styles and his or her emotions. The research, involving a sample of 99 students in Hongkong, was able to prove that the thinking style had the power to predict the emotions along with the development of age.

The consequences of the differences in students' emotional intelligence on the learning styles of VARK models are that learning should activate all senses, not only focusing on one of the senses. The practical implications of the results of this research are directed to the teacher as a designer, actor, and evaluator of learning. As a designer, teachers need to consider how to develop and to create a learning atmosphere or a learning environment which activates all the senses. As an actor of learning, teachers can begin with organizing learning material in such a way that attracts the students' attention, as well as stimulates the maximum use of all the senses. Teachers can select learning strategies or learning models which facilitate the use of multiple senses equally in receiving instructional information. Teachers can use learning media which support the learning strategy or learning model, as well as trigger various sensory organs to work, thus strengthening students' emotional intelligence. As an evaluator, a teacher can make an assessment or reflection to improve and refine the planning or the real action performed in learning activities. Teachers also need to reflect on whether or not their teaching styles have been able to accommodate all the characteristics of students' learning styles, and to encourage the development of students' emotional intelligence. In learning, teachers may need to introduce a variety of strategic ways of learning for students related to the VARK model, thus constructing the students' awareness of the strengths and weaknesses of their learning styles. It is expected that it motivates students to learn earnestly based on their unique learning styles. In relation to that, teachers, as the real models in learning, are believed to become the role models which practice mature emotional intelligence and support the learning conditions and the students' emotional development.

\section{Facts about Learning Style Changes}

Students' learning styles are influenced by various factors. These factors include physical, emotional, sociological, and environmental factors (Singh, 2014). When people have different learning styles, this will also lead to different emotional intelligence or learning results, although the patterns of learning and the learning materials are similar. A class as a learning community serves to accommodate a number of students in the same room and the same atmosphere during the learning process until the exam. However, learning styles may change along with the people's maturity development.

VARK learning style models are oriented on sensory modalities or human physiological dimension, namely by enabling the vision (visual), hearing (auditory), read (visual and touch) and kinesthetic (multisensory). VARK learning style models are easy to be implemented on students at different levels of education, and tend to be stable in certain situations. In addition, it provides an overview of learning method the students use (Rudman, Beer, \& Olorundju, 2015).

The distribution of learning styles at different levels of education varies. At the elementary school level in AmbonIndonesia, kinesthetic learning style is dominant compared to the visual, auditory, and read learning styles. The percentage of kinesthetic, auditory, read, and visual styles are $56.76 \%, 22.86 \%, 17.52 \%, 2.86 \%$ respectively (Leasa, 
2014). On the other hand, Saadi \& Abdulaziz (2014) using VARK model on junior high school students of class VII and VIII among 399 students in Saudi Arabia, reported that the percentage of visual, auditory, read, and kinesthetic models was $7 \%, 5 \%, 9 \%$ and $12 \%$ respectively. These data indicate that there has been a change in the learning styles. Visual learning style increases about $4.14 \%$, but auditory, read, and kinesthetic learning styles decrease by $17.86 \%$, $8.52 \%$, and $44.72 \%$ respectively. This change occurrs because at the level of junior high school, students tend to integrate more than one learning style, so the multimodal learning style percentage reaches $67 \%$.

The learning style change occurs at a higher level. Singh, Govil, and Rani (2015) reported that there was an increased percentage in all learning styles of senior high school students. Compared to that of junior high school level, the increase in visual learning style of senior high school reached $38.7 \%$, auditory reached $16 \%$, kinesthetic reached $3 \%$, and read reached $9.3 \%$. Thus, at senior high school level, the sequence of learning styles that tended to be applied was visual, auditory, read, and kinesthetic. The results of this research support the findings of Lisle (2007) conducting a research on adult students having mental disabilities. Her findings found that adult students tended to use visual and auditory learning styles compared to kinesthetic and read learning style.

Slater, Lujan, and DiCarlo (2007) reported that medical students had diverse learning styles. In their research 96 students were involved, and it was found that visual and auditory learning styles had the same percentage of 5.3\%, while read learning style was $10.6 \%$, and kinesthetic learning style was $22 \%$. The unimodal learning styles as a whole reached $43.2 \%$, while the multimodal was $56.8 \%$. These results show that in college level, learners tend to integrate more than two learning styles. The other research findings about the learning styles at the college level were reported by Wehrwein, Lujan, and DiCarlo (2007) on students majoring in physiology department. The percentage of female students having unimodal learning style was $54.2 \%$, in which the visual learning style was $4.2 \%$, auditory learning style $0 \%$, read learning style $16.7 \%$ and kinesthetic learning style 33\%; $45.8 \%$ students were classified as having multimodal learning style. This finding was supported by Peyman et al. (2014) stating that medical students preferred to use a multimodal learning style compared to unimodal learning style. They used a wide range of variation in independent learning activities and presentations in the classroom.

Based on the research findings presented above, it is concluded that learning styles tend to change along with the level of cognitive and mental development of a person. At the elementary level of education, learners tend to use kinesthetic learning styles, while at the high level of education/vocational education the learners tend to optimize the visual learning style. At the college level, the learners tend to leave from unimodal learning style toward multimodal learning style along with the development of learners. The other affecting factors are environmental factors such as teachers' teaching strategies which require the students to adapt on the learning patterns.

\section{Conclusion}

Based on the results of the discussion in this research, three conclusions will be described as follows.

1. There is a difference in students' emotional intelligence viewed from the learning styles.

2. Related to the emotional intelligence, kinesthetic learning style has a significant difference compared to auditory and read learning styles; the difference between the kinesthetic and auditory was as much as $8.35 \%$, while the difference between the kinesthetic and read was $6.11 \%$.

3. Learning styles are thought to be dynamic, depending on the cognitive and mental development, and the learning environment which can stimulate the learners to become adaptive.

\section{References}

Aliakbari, M., \& Nejadian, A. R. (2011). Trait emotional intelligence and learning styles: the case of Iranian english for academic purposes learners. Educational Psychology, 35(7), 1-17.

Ashdown, D. M., \& Bernard, M. E. (2012). Can explicit in social and emotional learning skills benefit the social-emotional development, well-being, and academic achievement of young children? Early Childhood Education Journal, 39(6), 397-405

Ashiabi, G. S. (2000). Promoting the emotional development of preschoolers. Early Childhood Education Journal, 28(2), 79-84.

Baş, G., \& Beyhan, Ö. 2010. Effects of multiple intelligences supported project-based learning on students' achievement levels and attitudes towards English lesson, International Electronic Journal of Elementary Education, 2(3): 365-385.

Brackett, M. A., Mayer, J. D., \& Warner, R. M. (2004). Emotional intelligence and its relation to everyday behavior. Personality and Individual Differences, 36, 1387-1402.

Berrocal, P. F., \& Ruiz, D. (2008). Emotional intellegence in education. Electronic Journal of Research in Educational Psychology, 6(15), 421-436.

Boone, R. T., \& Cunningham, J. G. (1998). Children's decoding of emotion in expressive body movement: the development of cue attunement. Developmental Psychology, 34(5), 1007-1016.

Caldarella, P. C. L., Kramer, J. T., \& Kronmiller, K. (2009). Promoting social and emotional learning in second grade students: a study of the strong start curriculum. Early Childhood Education Journal, 37, 51-56.

Cavanaugh, L. A., Maclnnis, D. J., \& Weiss, A. M. (2015). Perceptual dimensions differentiate emotions. Cognition and Emotion: 1-16. doi. 10.1080/02699931.2015.1070119.

Daşdemir, I. 2016. The effect of the 5E instructional model enriched with cooperative learning and animations on seventh-grade students' academic achievement 
and scientific attitudes. International Electronic Journal of Elementary Education, 9(1): 21-38.

Davis, S. A. (2007). Learning styles and memory. http://www.auburn.edu/.../ilsri/.../Learning Styles and Memory.pdf. Accessed on 27 September 2013.

Demir, S., Kilinc, M., \& Dogan, A. 2012. The effect of curriculum for developing efficient studying skills on academic achievements and studying skills of learners. International Electronic Journal of Elementary Education, 4(3): 427-440.

Dyck, E. V., Maes, P. Jan., Hargreaves, J., Lesaffre, M., \& Leman, M. (2013). Expressing induced emotions through free dance movement. Journal Nonverbal Behavior, 37, 175-190.

Downey, L. A., Lomas, J., Billings, C., Hansen, K., \& Stough, C. (2014). Scholastic success: fluid intelligence, personality, and emotional intelligence. Canadian Journal of School Psychology, 29(1), 40-53.

Eom, S. B., Wen, H. J., \& Ashill, N. (2006). The determinants of students' perceived learning outcomes and satisfaction in university online education: an empirical investigation. Decision Journal of Innovative Education, 4(2), 215-233.

Erwin, H., Fedewa, A., \& Ahn, S. 2013. Student academic performance outcomes of a classroom physical activity intervention: A pilot study. International Electronic Journal of Elementary Education, 5(2): 109124.

Fernandez, J. M. G., Ingles, C. J., Suria, R., Martin, N. L. S., Macia, C. G., Aparizi, D., \& Monteagudo, M. C. M. (2015). Profiles of emotional intelligence and learning strategy in a sample of Chilean students. European Journal of Psychology of Education, 30, 437455.

Fleming, N. D. (2001). Teaching and learning styles: VARK strategies. Christchurch, New Zealand.

Fong, O. P., \& Yeo, R. (2007). Influence of emotional intelligence on learning styles: an exploratory study on management undergraduates in Malaysia and Saudi Arabia. Enhancing Higher Education, Theory and Scholarship, Proceedings of the 30th HERDSA Annual Conference, Adelaide, 8-11 July 2007. (Online),

(www.herdsa.org.au/wpcontent/uploads/conference/2007/, accessed on 21 January 2015).

Furtner, M. R., Rauthmann, J. F., \& Sachse, P. (2010). The sosioemotionally intelligent self-leader: examining relations between self leadership and sosioemotional intelligence. Social Behavior and Personality, 38(9), 1191-1196.

Gardner, H. (1993). Multiple intelligences: the theory in practice. New York: Basic Books.

Ghuman, U. (2011). Building a model of group emotional intelligence. Team Performance Management, $17(7 / 8), 418-439$.
Goleman, D. (1995). Emotional intelligence: why it can matter more than IQ. New York: Bantam Books.

Goleman, D. (1998). Working with emotional intelligences. New York: Bantam Books.

Gunter, L., Caldarella, P., Korth, B. B., \& Young, K. R. (2012) Promoting social and emotional learning in preschool students: a study of strong start pre-K. Early Childhood Educ Journal, 40, 151-159.

Hanford, K. (2000). Wisdom in movement. California: Nord Press.

Hegarty, N., \& Angelidis, J. (2015). The impact of academic service learning as a teaching method and its effect on emotional intelligence. Journal of Academic Ethics, 13, 363-374.

Hertenstein, M. J., \& Keltner, D. (2011). Gender and the communication of emotion via touch. Sex Roles, 64, 70-80.

laosanurak, C., Chanchalor, S., \& Murphy, E. (2015). Social and emotional learning around technology in a cross-cultural, elementary classroom. Educ Inf Technol, 1-24.

Johnson, J. M., \& Stern, T. A. (2014). Teaching residents about emotional intelligence and its impact on leadership. Academic Psychiatry, 1-4.

Kwon, J. Y., \& Yakwey, T. D. (2003). Principles of emotional development and children's pretend play. International Journal of Early Childhood, 32(1), 9-13.

Leasa, M. (2014). Learning style preferences of elementary school students class VI in Ambon. Research Report Beginner Lecturer. Ambon: FKIP-Pattimura University.

Leasa, M., \& Samallo, R. (2014). Learning motivation of students in Ambon child-friendly school, Moluccas. Education, 4(2), 41-51.

Leiner, H. C. (2010). Solving the mystery of the human cerebellum. Neuropsychology Review, 20, 229-235.

Levine, L. J., \& Pizarro, D. A. (2004). Emotion and memory research. Social Cognition, 22(5), 530-554.

Lisle, A. M. (2007). Assessing learning styles of adults with intellectual difficulties. Journal of Intellectual Disabilities, 2(1), 23-45.

Mayer, J. D., \& Cobb, C. D. (2000). Educational policy on emotional intelligence: does it make sense? Educational Psychology Review, 12(2), 163-183.

McCleskey, J. (2012). Emotional intelligence and leadership. International Journal of Organizational Analysis, 22(1), 76-93.

Nelis, D., Quidbach, J., Mikolajczak, M., \& Hansenne, M. (2009). Increasing emotional intelligence: how is it possible? Personality and Individual Differences, 47, 36-41.

Othman, N., \& Amiruddin, M. H. (2010). Different perspective of learning styles from VARK model. 
Procedia Social and Behavioral Sciences, 7(C), 652660.

Peyman, H., Sadeghifar, J., Khajavikhan, J., Yasemi, M., Rasool, M., Yaghoub, Y. M., Nahal, M. H. M., \& Karim, H. (2014). Using VARK approach for assessing preferred learning styles of first year medical sciences students: a survey from Iran. Journal of Clinical and Diagnostic Research, 8(8), GC01-GC04.

Rudman, E., Beer, M. D., Olorundju, S. (2015). Learning styles of first year occupational therapy students studying at a university in South Africa. South African Journal of Occupational Therapy, 45(3), 23-27.

Saadi, I. A., \& Abdulaziz, K. (2014). Gender and learning styles in Saudi Arabia schools. The Clute Institute International Academic Conference. San Antonio, Texas USA.

Shahzada, G., Ghazi, S., Khan, A., Khan, H., \& Shah, M. (2011). The relationship of emotional intelligence with the students' academic achievement. Interdisciplinary Journal of Contemporary Research in Business, 3(1), 994-1001.

Singh, J. (2014). Effect of school and home factors on learning outcomes at elementary school level: a hierarchical linear model. Education 3-13: International Journal of Primary, Elementary and Early Years Education, 1-26.

Singh, L., Govil, P., \& Rani, R. (2015). Learning style preferences among secondary school students. International Journal of Recent Scientific Research, 6(5), 3924-3928.

Slater, J. A., Lujan H. L., \& DiCarlo S. E. (2007). Does gender influence learning style preference of first year medical student?. Advances in Physiology Education, 31, 336-342.

Thom, L. (2010). From simple line to expressive movement: the use of creative movement to enhance socioemotional development in the preschool curriculum. American Journal of Dance Therapy, 32, 100-112.

Tugade, M. M., \& Fredrickson, B. L. (2007). Regulation of positive emotions: emotion regulation strategies that promote resilience. Journal of Happiness Studies, 8, 311-333.

Vandervoort, D. (2006). The importance of emotional intelligence in higher education. Current Psychology, 25(1), 4-7.

Walter, O., \& Hen, M. (2012). Sherborne developmental movement (SDM) teaching model for pre service teachers. Support of Learning, 27(1), 20-30.

Walter, O., \& Sat, E. (2013). Dance and its influence on emotional self-control and regulation and emotional intelligence abilities among early childhood-aged children. International Journal of Arts \& Sciences, 6(4), 77-97.
Wehrwein, E. A., Lujan, H. L., \& DiCarlo, S. E. (2007). Gender differences in learning style preferences among undergraduate physiology students. Advances Physiology Education, 31, 153-157.

Zhang, F. L. (2008). Thinking styles and emotions. The Journal of Psychology, 142(5), 497-515. 
This page is intentionally left blank www.iejee.com 